\title{
9-Anthracene carboxylic acid is more suitable than DIDS for characterization of calcium-activated chloride current during canine ventricular action potential
}

\author{
Krisztina Váczi • Bence Hegyi • Ferenc Ruzsnavszky • \\ Kornél Kistamás • Balázs Horváth • Tamás Bányász • \\ Péter P. Nánási • Norbert Szentandrássy • János Magyar
}

Received: 1 August 2014 / Accepted: 21 September 2014

(C) Springer-Verlag Berlin Heidelberg 2014

\begin{abstract}
Understanding the role of ionic currents in shaping the cardiac action potential (AP) has great importance as channel malfunctions can lead to sudden cardiac death by inducing arrhythmias. Therefore, researchers frequently use inhibitors to selectively block a certain ion channel like 4,4'diisothiocyanostilbene-2,2'-disulfonic acid (DIDS) and 9anthracene carboxylic acid (9-AC) for calcium-activated chloride current $\left(\mathrm{I}_{\mathrm{Cl}(\mathrm{Ca})}\right)$. This study aims to explore which blocker

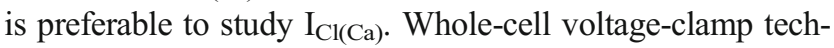
nique was used to record $\mathrm{I}_{\mathrm{Ca}, \mathrm{L}}, \mathrm{I}_{\mathrm{Ks}}, \mathrm{I}_{\mathrm{Kr}}$ and $\mathrm{I}_{\mathrm{K} 1}$, while action potentials were measured using sharp microelectrodes. DIDS$(0.2 \mathrm{mM})$ and 9 -AC-sensitive $(0.5 \mathrm{mM})$ currents were identical in voltage-clamp conditions, regardless of intracellular $\mathrm{Ca}^{2+}$ buffering. DIDS-sensitive current amplitude was larger with the increase of stimulation rate and correlated well with the rate-induced increase of calcium transients. Both drugs increased action potential duration (APD) to the same extent, but the elevation of the plateau potential was more pronounced with 9-AC at fast stimulation rates. On the contrary, 9-AC did not influence either the AP amplitude or the maximal rate of depolarization $\left(V_{\max }\right)$, but DIDS caused marked
\end{abstract}

\footnotetext{
K. Váczi • B. Hegyi · F. Ruzsnavszky • K. Kistamás • B. Horváth •

T. Bányász $\cdot$ P. P. Nánási $\cdot N$. Szentandrássy $(\bowtie) \cdot J$. Magyar

Department of Physiology, Faculty of Medicine, University of

Debrecen, 4012 DebrecenNagyerdei krt 98, Hungary

e-mail: szentandrassy.norbert@med.unideb.hu

B. Horváth

Faculty of Pharmacy, University of Debrecen, Debrecen, Hungary

P. P. Nánási $\cdot N$. Szentandrássy

Department of Dental Physiology and Pharmacology, Faculty of

Dentistry, University of Debrecen, Debrecen, Hungary

J. Magyar

Division of Sport Physiology, Department of Physiology, Faculty of

Medicine, University of Debrecen, Debrecen, Hungary
}

reduction of $V_{\max }$. Both inhibitors reduced the magnitude of phase-1, but, at slow stimulation rates, this effect of DIDS was larger. All of these actions on APs were reversible upon washout of the drugs. Increasing concentrations of 9-AC between 0.1 and $0.5 \mathrm{mM}$ in a cumulative manner gradually reduced phase-1 and increased APD. 9-AC at $1 \mathrm{mM}$ had no additional actions upon perfusion after $0.5 \mathrm{mM}$. The halfeffective concentration of 9-AC was approximately $160 \mu \mathrm{M}$ with a Hill coefficient of 2 . The amplitudes of $\mathrm{I}_{\mathrm{Ca}, \mathrm{L}}, \mathrm{I}_{\mathrm{Ks}}, \mathrm{I}_{\mathrm{Kr}}$ and $\mathrm{I}_{\mathrm{K} 1}$ were not changed by $0.5 \mathrm{mM} 9-\mathrm{AC}$. These results suggest that DIDS is equally useful to study $\mathrm{I}_{\mathrm{Cl}(\mathrm{Ca})}$ during voltageclamp but 9-AC is superior in AP measurements for studying the physiological role of $\mathrm{I}_{\mathrm{Cl}(\mathrm{Ca})}$ due to the lack of sodium channel inhibition. 9-AC has also no action on other ion currents $\left(\mathrm{I}_{\mathrm{Ca}, \mathrm{L}}, \mathrm{I}_{\mathrm{Kr}}, \mathrm{I}_{\mathrm{Ks}}, \mathrm{I}_{\mathrm{K} 1}\right)$; however, $\mathrm{I}_{\mathrm{Ca}, \mathrm{L}}$ tracings can be contaminated with $\mathrm{I}_{\mathrm{Cl}(\mathrm{Ca})}$ when measured in voltage-clamp condition.

Keywords Calcium-activated chloride current - Canine myocytes $\cdot 9-$ Anthracene carboxylic acid · DIDS · Action potential $\cdot$ Ion currents

\section{Introduction}

Sudden cardiac death as a result of cardiac arrhythmias is a major cause of death in western civilizations (Fishman et al. 2010). These arrhythmias are often due to malfunctions of cardiac ion channels (Schmitt et al. 2014). Therefore, understanding the role of ionic currents in shaping the cardiac action potential (AP) has great importance. This could be achieved by several approaches. One is to use expression systems to evaluate the biophysical properties of the current. However, the lack of other potentially important regulatory subunits or intracellular pathways could be a real disadvantage. Another 
possibility is to reduce the expression of the channel protein in cell culturing which is a rather difficult process in cardiomyocytes (Parameswaran et al. 2013). Carefully planned voltage-protocols together with the suppression of other currents could be used in native cardiac cells to isolate the examined current. These artificial conditions are sometimes very far from physiological ones; moreover, the behavior of various currents under an actual action potential can be drastically different from that recorded with conventional voltage-clamp (Fülöp et al. 2004). An ideal situation is to block the investigated channel with a selective inhibitor and measure the inhibitor-sensitive current either with conventional voltage-clamp or action potential voltage-clamp (Szentandrássy et al. 2011). This solution works very well only in those rare cases where a truly selective blocker is available.

Much information is already available about the contribution of various cationic currents to the cardiac AP, but anionic currents are much less well characterised (Duan 2009). One of these anionic currents is the calcium-activated chloride current $\left(\mathrm{I}_{\mathrm{Cl}(\mathrm{Ca})}\right)$ (Eggermont 2004). Regardless of the handful inhibitors used to inhibit this current, a large problem is the missing identity of the protein responsible for the generation of $\mathrm{I}_{\mathrm{Cl}(\mathrm{Ca})}$. The most likely candidate is the relatively newly identified TMEM16 protein (Yang et al. 2008; Forrest et al. 2012); however, the results are not absolutely conclusive yet. The discovery of TMEM16 also known as Anoctamin1, and the possibility that it is the ion channel responsible for $\mathrm{I}_{\mathrm{Cl}(\mathrm{Ca})}$ recently boosted the research in this field in smooth muscle (Dam et al. 2014), neuronal, and other tissues (Pedemonte and Galietta 2014), highlighting the importance of $\mathrm{I}_{\mathrm{Cl}(\mathrm{Ca})}$ in various physiological functions.

Traditional anion transporter inhibitors, such as 4,4'diisothiocyanostilbene-2,2'-disulfonic acid (DIDS) and 9anthracene carboxylic acid (9-AC) are still used to determine calcium-activated chloride current in different cell types, including cardiomyocytes. DIDS $(0.1-2 \mathrm{mM})$ is applied more frequently for this purpose (Zygmunt 1994; Kawano et al. 1995; Verkerk et al. 2002; Hirayama et al. 2002; Li et al. 2003; Guo et al. 2008) than 9-AC (0.5-1 mM) (Levesque et al. 1993; Fülöp et al. 2003). Many other compounds were used to inhibit chloride currents including another stilbene derivative 4-acetamido-4'-isothiocyanostilbene-2,2'-disulfonic acid (SITS, 1-2 mM) (Zheng et al. 2013; Guo et al. 2008; Zygmunt and Gibbons 1992), diphenylamine-2-carboxylate (DPC, 0.5-1 mM) (Walsh and Wang 1996), 5-nitro-2-(3phenylpropyl-amino) benzoic acid (NPPB) (Zheng et al. 2013) and also the widely applied niflumic acid (NFA, 30$200 \mu \mathrm{M})$ (Xu et al. 2002; Song et al. 2009; Forrest et al. 2012), just to list a few. These compounds should usually be used in a quite high concentration to achieve inhibition of the chloride channels. Moreover, they interact with ion channels found in the surface of the ventricular myocytes or possess other unwanted actions, thus their use to determine the physiological role of calcium-activated chloride current is limited. For instance, NFA $(100 \mu \mathrm{M})$ as well as NPPB $(50 \mu \mathrm{M})$ also block the L-type calcium current $\left(\mathrm{I}_{\mathrm{Ca}, \mathrm{L}}\right)$ by about $50 \%$ in isolated rat ventricular myocytes and reduce calcium transients and cell shortening (Zhou et al. 2002). NFA $(10 \mu \mathrm{M})$ also reduced calcium current in rat uterine cells (Jones et al. 2004). Regarding the pronounced calcium-dependent feature of $\mathrm{I}_{\mathrm{Cl}(\mathrm{Ca})}$, it is easy to imagine the magnitude of error introduced by blocking such a huge fraction of $\mathrm{I}_{\mathrm{Ca}, \mathrm{L}}$ by NFA or NPPB. Moreover, the upstroke of the AP was reduced in a dosedependent manner with $\mathrm{IC}_{50}$ values of approximately 70 and $12 \mu \mathrm{M}$ by NFA and NPPB, respectively (Zhou et al. 2005). Both blockers reduced sodium current $\left(\mathrm{I}_{\mathrm{Na}}\right)$ and induced a leftward shift in its steady-state inactivation (Zhou et al. 2005). NFA induced an outward current at $0 \mathrm{mV}$ in rat ventricular myocytes in a tyrosine kinase signaling pathwaymediated manner (Zhou et al. 2007). Another study described a great reduction of the current flowing through $\mathrm{K}_{\mathrm{v}} 4.3$ and $\mathrm{K}_{\mathrm{v}} 4.2$ potassium channels by $100 \mu \mathrm{M}$ NFA as well as the alteration of steady-state inactivation (Wang et al. 1997). Interestingly, the same study reported differential actions of SITS $(2 \mathrm{mM})$ on the kinetic behavior as it markedly reduced the recovery from inactivation without altering the steadystate inactivation curve (Wang et al. 1997). DPC (0.5$1 \mathrm{mM}$ ) also proved to be non-selective as it reduced forskolin-stimulated $\mathrm{I}_{\mathrm{Ca}, \mathrm{L}}$ measured in guinea pig ventricular myocytes and in mouse atrial myocytes (Walsh and Wang 1996).

Due to the previously described lack of specificity of commonly applied chloride channel inhibitors, the aim of the present study was to explore whether DIDS or 9-AC is preferable to study $\mathrm{I}_{\mathrm{Cl}(\mathrm{Ca})}$ in native left ventricular cardiomyocytes of the dog. Whole-cell voltage-clamp technique was used to record $\mathrm{I}_{\mathrm{Ca}, \mathrm{L}}, \mathrm{I}_{\mathrm{Ks}}, \mathrm{I}_{\mathrm{Kr}}$ and $\mathrm{I}_{\mathrm{K} 1}$, while action potentials were measured using sharp microelectrodes. Our results suggest that DIDS is equally useful to study $\mathrm{I}_{\mathrm{Cl}(\mathrm{Ca})}$ during voltage-clamp, but 9-AC is superior in AP measurements for studying the physiological role of $\mathrm{I}_{\mathrm{Cl}(\mathrm{Ca})}$ due to the lack of $\mathrm{I}_{\mathrm{Na}}$ inhibition.

\section{Materials and methods}

\section{Cell isolation}

Experiments were carried out on canine left ventricular myocytes according to a protocol approved by the local ethical committee and conform to the principles outlined in the Declaration of Helsinki. Adult beagle dogs of both sexes were anesthetised by the intramuscular application of the mixture of $10 \mathrm{mg} / \mathrm{kg}$ ketamine hydrochloride (Calypsol, Richter Gedeon, Budapest, Hungary) and $1 \mathrm{mg} / \mathrm{kg}$ xylazine hydrochloride 
(Sedaxylan, Eurovet Animal Health BV, Bladel, The Netherlands). After the establishment of complete narcosis, the chest was opened, and hearts were quickly removed followed by washing with Tyrode solution (composition in $\mathrm{mM}, \mathrm{NaCl}, 144 ; \mathrm{KCl}, 5.6 ; \mathrm{CaCl}_{2}, 2.5 ; \mathrm{MgCl}_{2}, 1.2$; 4-(2-Hydroxyethyl)piperazine-1-ethanesulfonic acid (HEPES), 5; and dextrose, 11; at $\mathrm{pH}=7.4$.). The atria were removed, and then the left anterior descendent coronary artery (LAD) was cannulated. A wedge-shape region of the left ventricle containing the region supplied by the LAD was cut out from the heart. This region was perfused with a nominally $\mathrm{Ca}^{2+}$ free JMM solution (Minimum Essential Medium Eagle, Joklik Modification, Sigma-Aldrich Co., St. Louis, MO, USA) supplemented with the followings: taurine, $2.5 \mathrm{~g} / \mathrm{L}$; $\mathrm{NaH}_{2} \mathrm{PO}_{4}, 200 \mathrm{mg} / \mathrm{L} ; \mathrm{NaHCO}_{3}, 1.4 \mathrm{~g} / \mathrm{L}$; pyruvic acid, $175 \mathrm{mg} / \mathrm{L}$; allopurinol, $13.5 \mathrm{mg} / \mathrm{L}$; D-ribose, $750 \mathrm{mg} / \mathrm{L}$ and having $\mathrm{pH}$ of 6.8. After $5 \mathrm{~min}$ of perfusion to remove the blood from the tissue, $1 \mathrm{~g} / \mathrm{L}$ collagenase (Type II.; Worthington Biochemical Co., Lakewood, NJ, USA), 2 g/L bovine serum albumin (Fraction V.; Sigma-Aldrich Co., St. Louis, MO, USA) and $50 \mu \mathrm{M} \mathrm{CaCl} 2$ were added to the solution. Enzymatic digestion took usually 25-35 min which was followed by the collection of isolated myocytes. During the enzymatic digestion, the solutions were kept at $37^{\circ} \mathrm{C}$ and gassed with a mixture of $95 \% \mathrm{O}_{2}$ and $5 \% \mathrm{CO}_{2}$. The tissue was cut with a scalpel, and the middle portion of the free ventricular wall containing mainly mid-myocardial cells was cut into pieces, sedimented, and filtered several times to remove big chunks. During this procedure, the calcium level of the solution was gradually raised to the final $2.5 \mathrm{mM}$. Cells were placed into MEM solution (Sigma-Aldrich Co., St. Louis, MO, USA) supplemented with the following: taurine, $2.5 \mathrm{~g} / \mathrm{L} ; \mathrm{NaH}_{2} \mathrm{PO}_{4}, 200 \mathrm{mg} / \mathrm{L} ; \mathrm{NaHCO}_{3}, 2 \mathrm{~g} / \mathrm{L}$; pyruvic acid, $175 \mathrm{mg} / \mathrm{L}$; allopurinol, $13.5 \mathrm{mg} / \mathrm{L}$; D-ribose, $750 \mathrm{mg} / \mathrm{L}$ having $\mathrm{pH}$ of 7.3 and stored at $15{ }^{\circ} \mathrm{C}$ until use but maximum 2 days. The percentage of living cells having clear cytoplasm and sharp edges showing clear striations were usually $30-60 \%$, and only these were used for electrophysiological recordings.

\section{Electrophysiology}

Cells were placed in a plexiglass chamber with a volume of approximately $1 \mathrm{~mL}$ and perfused with a gravity driven system at a speed of $2 \mathrm{~mL} / \mathrm{min}$. All experiments were done at $37^{\circ} \mathrm{C}$ and $\mathrm{pH}=7.4$ in Tyrode solution (composition in millimolars, $\mathrm{NaCl}, 144 ; \mathrm{KCl}, 5.6 ; \mathrm{CaCl}_{2}, 2.5 ; \mathrm{MgCl}_{2}, 1.2$; HEPES, 5 ; and dextrose, 11). The cells were visualised by an inverted microscope (Eclipse TE2000-U, Nikon, Japan) placed in a Faraday cage on an anti-vibration table. Electrical signals were recorded with intracellular amplifiers (MultiClamp $700 \mathrm{~A}$ and $700 \mathrm{~B}$ or AxoClamp 2B, Molecular Devices, Sunnyvale, CA, USA) after analogue-digital conversion
(Digidata 1440 A or 1332 , Molecular Devices, Sunnyvale, CA, USA) and recorded with pClamp 10 or 9 softwares (Molecular Devices, Sunnyvale, CA, USA).

\section{Action potential measurements}

APs were recorded in current-clamp mode with borosilicate microelectrodes filled with $3 \mathrm{M} \mathrm{KCl}$ having a tip resistance of 20-50 MOhm. Stimulation occurred in steady-state conditions at variable cycle length elicited by 1-2-ms-long current pulses having sizes of 120 $130 \%$ of threshold produced by an electronic stimulator (DS-R3; Fönixcomp Ltd, Hungary). Upon the analysis of APs, the following parameters were determined: $\mathrm{APD}_{90}$ value (duration of the AP from the peak to $90 \%$ of repolarization), phase-1 magnitude (voltage difference between the AP peak and the minimal voltage value preceding the dome of the AP), $V_{\max }$ (the maximal rate of depolarization) and plateau potential (the value of the membrane potential at the point corresponding to the half duration of $\mathrm{APD}_{90}$ ).

\section{Voltage-clamp}

Ion currents were measured in whole-cell configuration of the patch-clamp technique (Hamill et al. 1981) and evoked by the stimulation of square voltage pulses. Upon determination of chloride channel blocker-sensitive currents, the signals evoked by voltage pulses were measured in Tyrode solution first then the measurement was repeated in the presence of the blocker. The blocker-sensitive currents were calculated by deducing the current traces measured in the presence of the blocker from those in the absence of the blocker (control). The internal solution for these measurements was the following: (in millimolars) $\mathrm{K}$-aspartate, 110; $\mathrm{KCl}, 45 ; \mathrm{MgCl}_{2}, 1$; HEPES, 5; and K-ATP, 3, $\mathrm{pH}=$ 7.2. In some experiments, indicated on the figures and text, $10 \mathrm{mM}$ BAPTA was used in the pipette, and the concentration of K-aspartate was reduced by $10 \mathrm{mM}$. For measuring $\mathrm{K}^{+}$currents, the internal solutions were made of (in millimolars) K-aspartate, $100 ; \mathrm{KCl}, 45$; $\mathrm{MgCl}_{2}, 1$; HEPES, 5; ethylene glycol tetraacetic acid (EGTA), 10; and K-ATP, 3, pH=7.2. In case of L-type $\mathrm{Ca}^{2+}$ current $\left(\mathrm{I}_{\mathrm{Ca}, \mathrm{L}}\right)$ measurement, the internal solution contained (in millimolars) $\mathrm{KCl}, 110$; $\mathrm{KOH}, 40$; HEPES, 10; EGTA, 10; tetraethylammonium chloride (TEACl), 20; K-ATP, 3, $\mathrm{pH}=7.2$.

Every chemical was purchased from Sigma-Aldrich Co., St. Louis, MO, USA. Voltage protocols and further information will be given at the appropriate section on "Results". Current signals were normalised to cell capacitance measured with 15 -ms-long hyperpolarizing pulses from 0 to $-10 \mathrm{mV}$. 
The osmolarity of all applied solution was carefully adjusted to $295 \pm 3 \mathrm{mOsm}$ with a vapor pressure osmometer (Vapro 5520, Wescor Inc., Logan, UT, USA).

\section{Intracellular calcium measurements}

Changes in intracellular free $\mathrm{Ca}^{2+}$ concentration were assessed by epifluorescence technique using the ratiometric dye, Fura2-AM. Myocytes were loaded in Tyrode solution with the membrane-permeant form of $3 \mu \mathrm{M}$ Fura- 2 in the presence of Pluronic F-127 for $10 \mathrm{~min}$ at room temperature. A period of at least $30 \mathrm{~min}$ was allowed for de-esterification of the dye at room temperature, and then cells were stored at $15{ }^{\circ} \mathrm{C}$ until experiments done within $24 \mathrm{~h}$.

Loaded cells were placed in a 1-ml-volume superfusion chamber on the stage of an inverted microscope (Eclipse TE2000-U, Nikon, Japan) and viewed using a $\times 40$ oil immersion objective (CFI S-Fluor $\times 40$ oil, Nikon). During experiments, the bath temperature was set to $37^{\circ} \mathrm{C}$ by a temperature controller (Cell MicroControls, Norfolk, VA, USA).

Cells were field-stimulated through a pair of platinum wires. Rectangular pulses, having durations of 1-2 ms and amplitudes of $120-130 \%$ of threshold, were generated by an electronic stimulator (DS-R3; Fönixcomp Ltd, Hungary) and delivered at a steady-state frequency of $0.2-3.33 \mathrm{~Hz}$.

Cells were excited with 340 and $380 \mathrm{~nm}$ light from a xenon arc lamp (Ushio Deutschland GmbH, Steinhöring, Germany). Excitatory wavelengths were altered by a dual-wavelength excitation monochromator and an online connected microcomputer (DeltaScan, Photon Technology International, New Brunswick, NJ, USA). Fluorescence emission was monitored at $510 \mathrm{~nm}$ using a R1527P photomultiplier tube (Hamamatsu Photonics Deutschland GmbH., Herrsching am Ammersee, Germany) at an acquisition rate of $500 \mathrm{~Hz}$. Changes in intracellular free $\mathrm{Ca}^{2+}$ levels were approximated by the ratio of the fluorescence intensity obtained at 340 and $380 \mathrm{~nm}$ excitation after correction for nonspecific background fluorescence and recorded using FeliX32 Software and BryteBox Interface (Photon Technology International, New Brunswick, NJ, USA). Ten consecutive calcium transients were averaged and analysed offline. The measured parameters were the baseline and peak fluorescence values, as well as the amplitude of the transient, calculated as a difference between the previous two values.

\section{Statistical evaluation}

Paired or unpaired Student's $t$ test followed by one-way ANOVA was used where appropriate to determine statistical significance. Differences were considered to be significant when $p<0.05$ and were marked with asterisks on figures.

\section{Results}

Calcium-activated chloride current measured as either DIDSor 9-AC-sensitive current is identical during conventional voltage-clamp recording

Conventional voltage-clamp technique was applied first to investigate $\mathrm{I}_{\mathrm{Cl}(\mathrm{Ca})}$ in canine left ventricular cardiomyocytes. The current was measured with the application of the two typically and often used inhibitors: $0.2 \mathrm{mM}$ DIDS or $0.5 \mathrm{mM}$ 9-AC. Cells were clamped to $-40 \mathrm{mV}$ as the holding potential, and the current was activated by 200 ms-long voltage steps applied between -100 and $+100 \mathrm{mV}$ with $20 \mathrm{mV}$ increments in every $5 \mathrm{~s}$. DIDSor 9-AC-sensitive current was determined by deducting the current traces measured in the presence of the inhibitor from those recorded in the absence of them and normalised to cell capacitance. DIDS-sensitive current traces showed rapid activation and reached their peak values within approximately $10 \mathrm{~ms}$ (Fig. 1a) which was also the case for 9-AC-sensitive currents (Fig. 1b). Interestingly, not only the activation, but the decay of the current was also fairly rapid. The current decreased to near zero $100 \mathrm{~ms}$ after the onset of the depolarizing pulse (Fig. 1a-b). Blocker-sensitive current amplitudes were determined as the difference between the peak values (measured between 5-20 ms) and the pedestal values (measured at the end of the voltage pulse). Currents activated at potentials higher than $-40 \mathrm{mV}$, and its current-voltage relationship had a bell-shaped curve with a peak value at $+60 \mathrm{mV}$ (Fig. 1c). In these experiments, the pipette solution did not contain EGTA or BAPTA ("without $\mathrm{Ca}^{2+}$ buffering" condition, Fig. 1c) and the currentvoltage relationships in case of the two tested drugs were practically identical. To test the calcium sensitivity of $\mathrm{I}_{\mathrm{Cl}(\mathrm{Ca})}$, experiments were repeated with the application of both inhibitors in a condition when intracellular $\mathrm{Ca}^{2+}$ concentration $\left(\left[\mathrm{Ca}^{2+}\right]_{i}\right)$ was buffered with the application of $10 \mathrm{mM}$ BAPTA in the patch-pipette ("with $\mathrm{Ca}^{2+}$ buffering" condition, Fig. 1d). DIDS- as well as 9-ACsensitive currents were again identical and practically zero at every potential (Fig. 1d). To further prove the calcium-dependent nature of $\mathrm{I}_{\mathrm{Cl}(\mathrm{Ca})}$, DIDS-sensitive currents were measured with a 200-ms-long voltage step elicited from $-40 \mathrm{mV}$ as the holding potential to $+60 \mathrm{mV}$. This stimulation was applied at various rates between 0.2 and $2 \mathrm{~Hz}$. The increase in the stimulation rate resulted in the increase of the amplitude of $\mathrm{I}_{\mathrm{Cl}(\mathrm{Ca})}$ (Fig. 1g). Intracellular calcium transients evoked by field stimulation also showed a rate-dependent behavior. All three studied parameters (peak, baseline and amplitude) increased upon the increase in the rate of stimulation (Fig. 1e-f). A good linear correlation was found 
between the amplitude of $\mathrm{I}_{\mathrm{Cl}(\mathrm{Ca})}$ and all studied parameters of the calcium transients. For instance, when values of $\mathrm{I}_{\mathrm{Cl}(\mathrm{Ca})}$ amplitude and peak values of calcium transients, all normalised to respective values measured at $1 \mathrm{~Hz}$ were fitted the value of $r^{2}$ was 0.996 (Fig. 1h).

Comparison of the effects of DIDS and 9-AC on the action potential measured with sharp microelectrode

Current-clamp studies were conducted in canine left ventricular cardiomyocytes where the actions on various parameters of the AP were determined. During these measurements, the conditions are somewhat similar to those in "without $\mathrm{Ca}^{2+}$ buffering" condition as there is no dialysis of the cell in sharp microelectrode recordings. APs were recorded at five different steady-state cycle lengths (starting with the longest and applying progressively shorter ones) in control condition. This was followed by the application of either $0.2 \mathrm{mM}$ DIDS or $0.5 \mathrm{mM}$ 9-AC. After the changes induced by the inhibitors reached a steady level (usually within $7-8 \mathrm{~min}$ ), the AP measurements at the different cycle lengths were repeated. As the last step, the washout of the inhibitors was performed to test the reversibility of the changes. The AP parameters of the control condition at $1 \mathrm{~Hz}$ were the following: $-80.7 \pm$
Fig. 1 Blocker-sensitive currents recorded in canine left ventricular myocytes. a Superimposed DIDSsensitive current traces at test potentials from -100 to $+100 \mathrm{mV}$ (shown on the insert). $\mathbf{b}$ Superimposed 9-AC-sensitive current traces. Current-voltage relationship of the DIDS- and 9-AC-sensitive current is shown on panel $\mathbf{c}$ in the absence and on panel $\mathbf{d}$ in the presence of intracellular calcium buffering. Calcium buffering was achieved by the application of $10 \mathrm{mM}$ BAPTA in the pipette solution. $\mathbf{e}$ Superimposed calcium transients obtained in field-stimulated cells at various rate of stimulation with FURA-2 indicator. Horizontal lines in front of each trace indicate the fluorescence values during diastole. $\mathbf{f}$ Various parameters of calcium transients (peak, baseline and amplitude) as a percent of those measured at $1 \mathrm{~Hz}$ plotted as a function of stimulation cycle length. Symbols (asterisk, minus sign and plus sign for baseline, peak and amplitude, respectively) show significant difference from $1 \mathrm{~Hz}$ data. $\mathrm{g} \mathrm{I}_{\mathrm{Cl}(\mathrm{Ca})}$ amplitude (measured as DIDS-sensitive current) as a percent of that measured at $1 \mathrm{~Hz}$ plotted as a function of stimulation cycle length. Asterisks denote significant difference from $1 \mathrm{~Hz}$ data. $\mathbf{h}$ Normalised $\mathrm{I}_{\mathrm{Cl}(\mathrm{Ca})}$ amplitude values (same as on panel g) plotted as a function of normalised peak values of calcium transients (same as upward triangles on panel f). Dashed line shows the linear fit, and $r^{2}$ is the correlation coefficient. Symbols and bars represent mean \pm SEM values; $n$ indicates the number of experiments
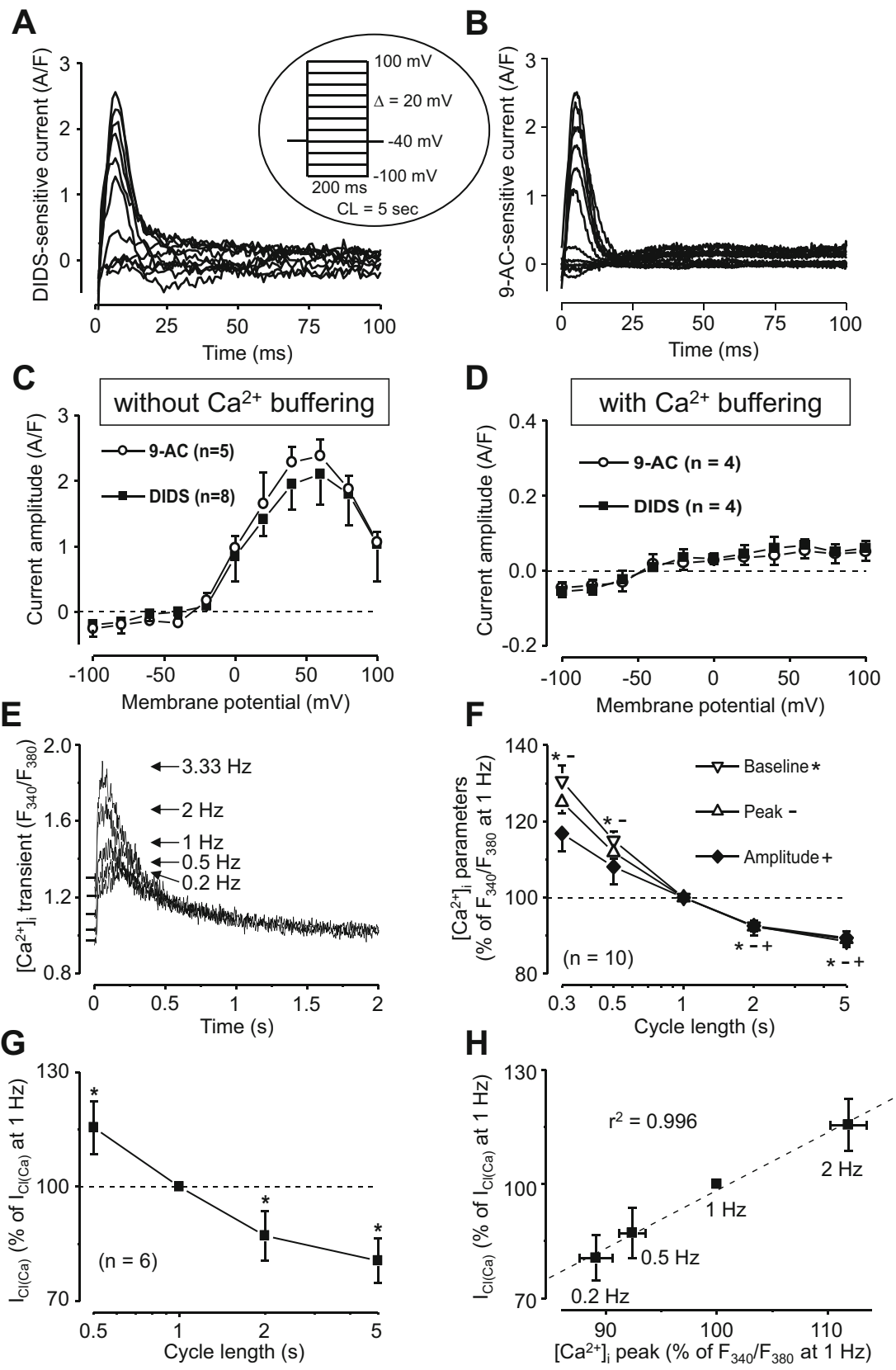
$0.7 \mathrm{mV}$ for resting membrane potential, $233.0 \pm 9.1 \mathrm{~ms}$ for $\mathrm{APD}_{90}, 22.3 \pm 2.1 \mathrm{mV}$ for phase-1 magnitude, $250.8 \pm 54.1 \mathrm{~V} / \mathrm{s}$ for $V_{\max }$ and $4.5 \pm 2.0 \mathrm{mV}$ for plateau potential $(n=21)$. The contours of the APs were modified by the two inhibitors in a similar fashion except the upstroke of the AP (Fig. 2a-b). Action potential duration was determined at the level of $90 \%$ repolarization $\left(\mathrm{APD}_{90}\right)$ and increased by both inhibitors in a similar, reverse rate-dependent manner (Fig. 2c). Phase-1 magnitude was determined as the difference between the membrane potential values of the peak and the deepest point of the notch. The reduction in phase-1 was observed by both inhibitors, but the cycle length dependence of the magnitude of this reduction was different (Fig. 2d). There was a greater reduction at long cycle length with 9-AC whereas the opposite was the case for DIDS, leading to a significantly greater reduction at 2- and 5-s-long cycle lengths compared with that seen with 9-AC. In case of DIDS, this change was similar in every studied cycle length and smaller compared with that seen in 9-AC at cycle lengths of 0.3 and $0.5 \mathrm{~s}$. Both the amplitude of the AP (not shown) and the value of $V_{\max }$ (Fig. 2e) were reduced by only DIDS whereas 9-AC did not influence these parameters. The plateau potential, measured at the $50 \%$ of $\mathrm{APD}_{90}$, was dependent on the rate of stimulation only if 9-AC was applied and the increase in the plateau potential was greater at short cycle lengths (Fig. 2f). The values of the resting membrane potential were not altered by either DIDS or 9-AC.

\section{Dose-dependent effects of 9-AC on the AP}

Current-clamp studies were continued to determine whether the previously applied dose of 9-AC was sufficient to achieve maximal inhibition of $\mathrm{I}_{\mathrm{Cl}(\mathrm{Ca})}$. In these experiments, the stimulation cycle length was $1 \mathrm{~s}$, and increasing concentrations of
Fig. 2 Comparison of the effects of DIDS and 9-AC on cardiac AP. a, b Representative APs measured by sharp microelectrodes in control, in the presence of chloride channel blockade achieved by either DIDS (panel a) or 9-AC (panel b) followed by washout of the inhibitors. The circled inserts show the upstroke of these APs and the following $15-20 \mathrm{~ms}$ enlarged. $\mathbf{c}-\mathbf{f}$ Changes of various AP parameters induced by either DIDS (filled squares) or 9-AC (open circles) as a function of cycle length of steady-state stimulation. Symbols and bars represent mean \pm SEM values; asterisks denote significant changes from control $(p<0.05)$; plus signs show significant difference between the actions of the two inhibitors, and $n$ indicates the number of experiments
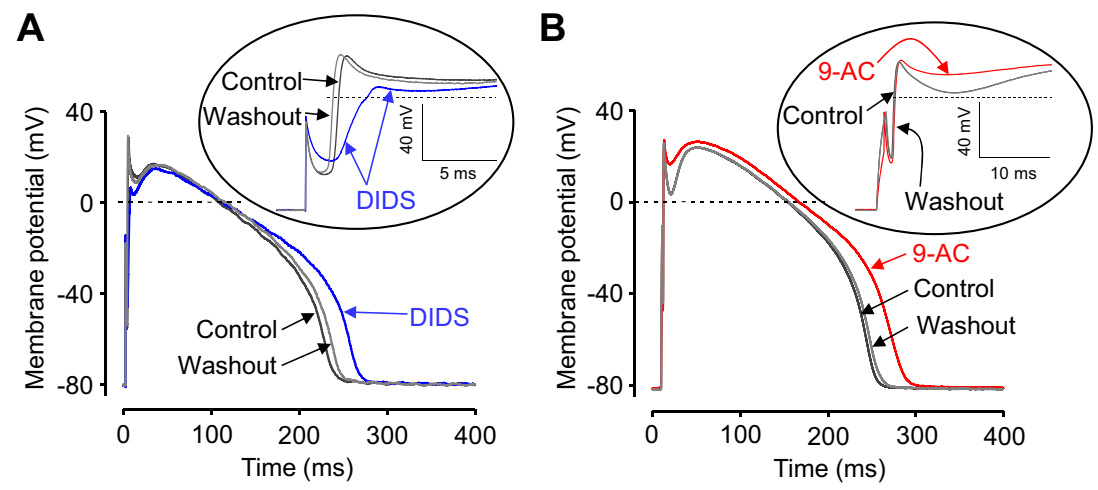

C

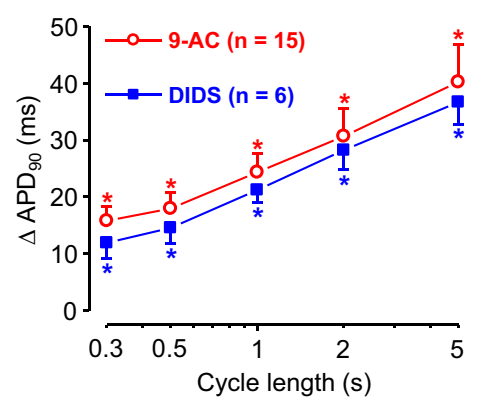

E

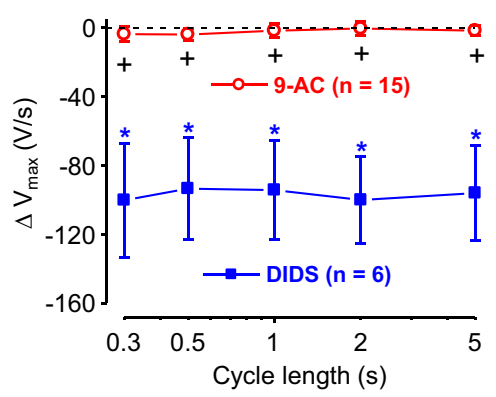

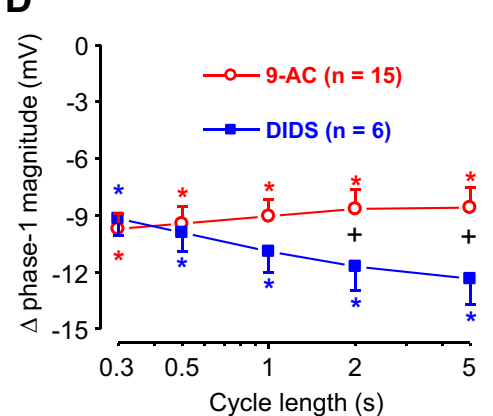

$\mathbf{F}$

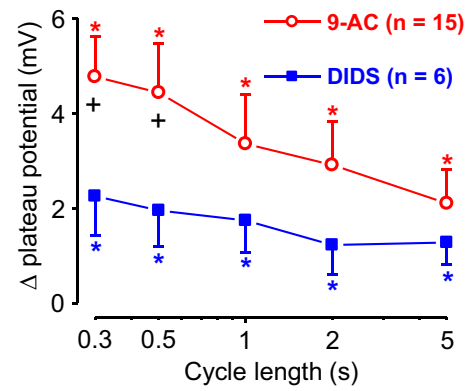


9-AC were applied in a cumulative manner in the range of $0.05-1 \mathrm{mM}$. As mentioned with the previous experiments, it took 7-8 min to reach steady-state actions of the inhibitor; therefore, at least $7 \mathrm{~min}$ of perfusion period was used for each dose. The previously seen reduction of phase- 1 and increases in plateau potential and $\mathrm{APD}_{90}$ values evoked by $9-\mathrm{AC}$ developed gradually by increasing concentrations of the inhibitor (Fig. 3a). The smallest dose evoking significant action on both $\mathrm{APD}_{90}$ and phase- 1 values was $0.3 \mathrm{mM}$ (Fig. $3 \mathrm{~b}-\mathrm{c}$ ). The application of $1 \mathrm{mM} 9-\mathrm{AC}$ did not increase the changes of AP parameters evoked by the previous dose of $0.5 \mathrm{mM} 9-\mathrm{AC}$ any further (Fig. 3b-c). The 9-AC-induced changes of phase-1 magnitude and $\mathrm{APD}_{90}$ values were converted to give a range of $0-100 \%$ in a way that the maximal change induced by the highest applied dose of 9-AC was considered as $100 \%$. Those converted values, obtained in each of ten measurements, were averaged and plotted on Fig. 3d-e as a function of 9-AC concentration. These points were fitted to Hill equation $(y=$ $1 /\left(1+\left(\mathrm{EC}_{50} / x\right)^{\wedge} n\right)$ where $\mathrm{EC}_{50}$ is the half-effective 9 -AC concentration and $n$ is the Hill coefficient. $\mathrm{EC}_{50}$ values were 167.2 \pm 12.4 and $158.2 \pm 8.2 \mu \mathrm{M}$ whereas Hill coefficients were $2.04 \pm 0.22$ and $1.81 \pm 0.13$ in cases of 9-AC-induced changes of phase-1 magnitude and $\mathrm{APD}_{90}$, respectively.

Effects of 9-AC on various cardiac cationic currents measured by conventional voltage-clamp

The previous current-clamp studies showed the similarities as well as the difference in the actions of DIDS and 9-AC on the AP of canine left ventricular myocytes. The reduction of AP amplitude and $V_{\max }$ in case of DIDS suggested the inhibition of sodium channels by that inhibitor. This action was not seen
Fig. 3 Cumulative dosedependent effect of 9-AC on ventricular AP. a Representative APs measured by sharp microelectrodes in control, in the presence of various concentrations of 9-AC followed by washout of 9-AC. The circled insert shows the phase-1 of these APs enlarged. $\mathbf{b}$, $\mathbf{c}$ Values of phase-1 magnitude (panel $\mathbf{b}$ ) and $\mathrm{APD}_{90}$ (panel c) in control, in the presence of increasing concentrations of 9-AC followed by washout of the blocker. $\mathbf{d}, \mathbf{e}$ Cumulative dose-dependent 9-AC-induced changes of phase-1 magnitude (panel d) and $\mathrm{APD}_{90}$ (panel e) normalised to the maximal changes. Points were fitted to Hill equation resulting in the solid lines. Parameters on the figures show the values \pm SEM of half effective concentration $\left(\mathrm{EC}_{50}\right)$ and Hill coefficients. Columns or symbols and error bars are mean \pm SEM values; $n$ indicates the number of experiments

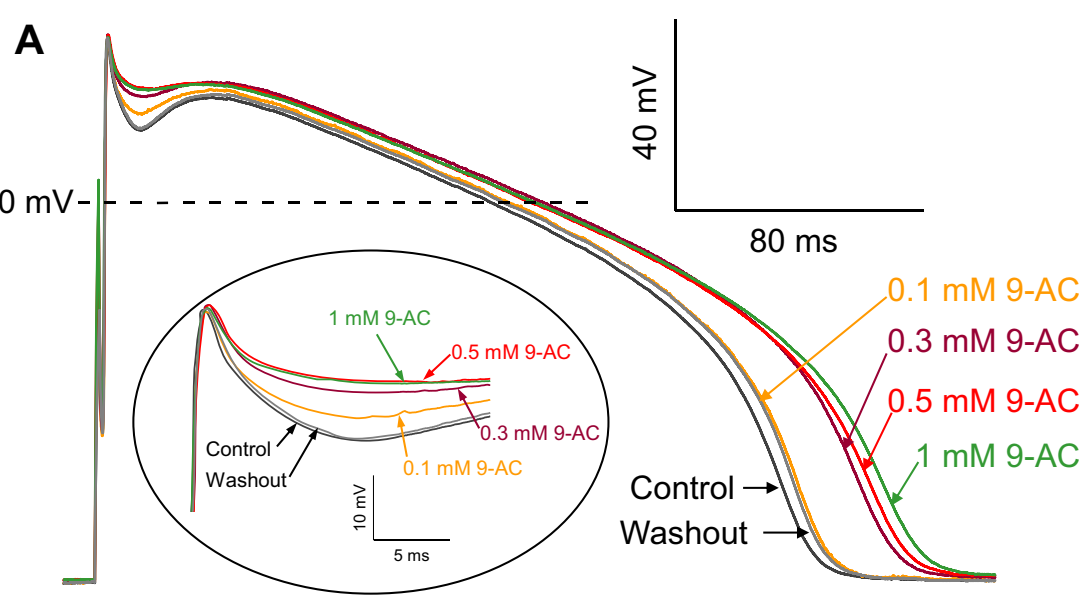

B

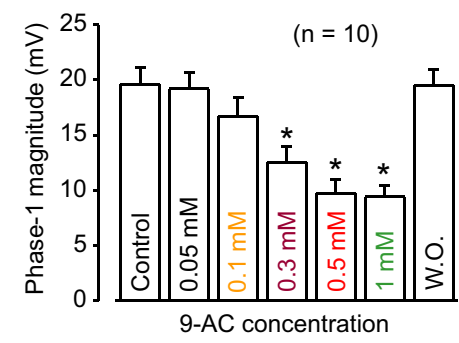

D

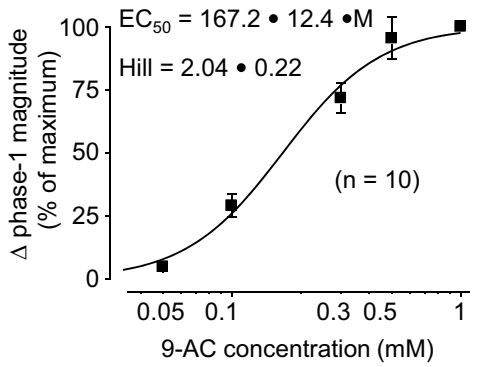

C

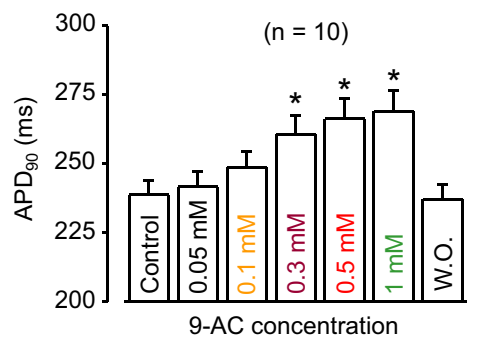

E

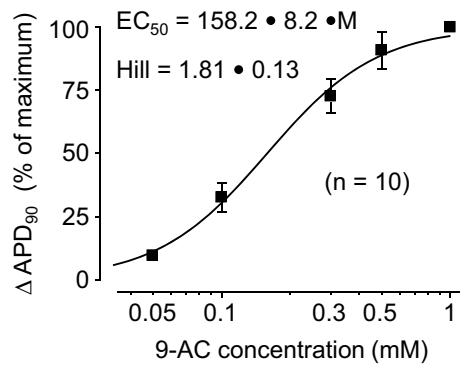


with the application of 9-AC even in the highest applied dose $(1 \mathrm{mM})$. To further test the possible non-selective actions of 9-AC, the major cationic currents were measured in control conditions and after the application of $10 \mathrm{~min}$ of $0.5 \mathrm{mM} 9$ AC (Fig. 4).

\section{Effects of 9-AC on the L-type calcium current $\left(I_{C a, L}\right)$}

$\mathrm{I}_{\mathrm{Ca}, \mathrm{L}}$ was activated by 400 -ms-long depolarizations to $+5 \mathrm{mV}$, arising from the holding potential of $-40 \mathrm{mV}$ at a rate of $0.2 \mathrm{~Hz}$. In these experiments, Tyrode solution was supplemented with $3 \mathrm{mM} 4$-aminopyridine (to block the transient outward potassium current, $\mathrm{I}_{\text {to1 }}$ ), $1 \mu \mathrm{M} \mathrm{E}-4031$ (selective $\mathrm{I}_{\mathrm{Kr}}$ inhibitor) and $1 \mu \mathrm{M}$ HMR-1556 (selective $\mathrm{I}_{\mathrm{Ks}}$ inhibitor) in order to block potassium currents. The amplitude of $\mathrm{I}_{\mathrm{Ca}, \mathrm{L}}$ was unaltered by 9 -AC. In the six studied cells, $\mathrm{I}_{\mathrm{Ca}, \mathrm{L}}$ density was $-5.34 \pm 0.44 \mathrm{~A} / \mathrm{F}$ in control condition and $-5.27 \pm 0.44 \mathrm{~A} / \mathrm{F}$ in the presence of 9-AC (Fig. 4b). It must be highlighted, however, that the inactivation of $\mathrm{I}_{\mathrm{Ca}, \mathrm{L}}$ largely overlaps with $\mathrm{I}_{\mathrm{Cl}(\mathrm{Ca})}$ as the decay of the current was much faster in control condition compared with that seen in the presence of 9-AC. Indeed, when calculating the 9-AC-sensitive current from the two
Fig. 4 Effect of $0.5 \mathrm{mM} 9$-AC on major ventricular ion currents. Representative recording showing $\mathrm{I}_{\mathrm{Ca}, \mathrm{L}}$ current (panel a), $\mathrm{I}_{\mathrm{Kr}}$ tail current (panel c), $\mathrm{I}_{\mathrm{Ks}}$ tail current (panel e) and $\mathrm{I}_{\mathrm{K} 1}$ current (panel g). Current amplitudes in control and in the presence of $0.5 \mathrm{mM} 9-\mathrm{AC}$ are depicted on panels on the right (b for $\mathrm{I}_{\mathrm{Ca}, \mathrm{L}}, \mathbf{d}$ for $\mathrm{I}_{\mathrm{Kr}}, \mathbf{f}$ for $\mathrm{I}_{\mathrm{Ks}}$ and $\mathbf{h}$ for $\mathrm{I}_{\mathrm{K} 1}$ ). Columns and bars are mean \pm SEM values; $n$ indicates the number of experiments
A

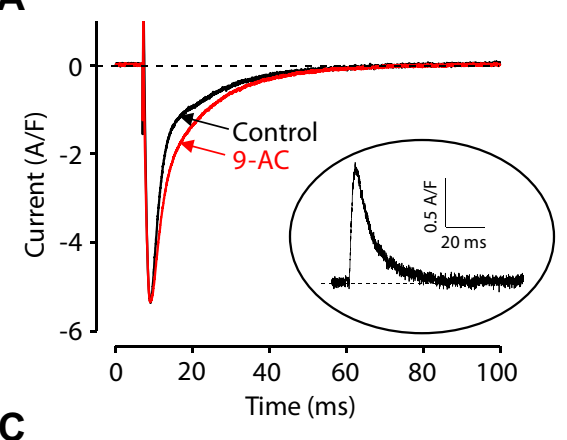

C

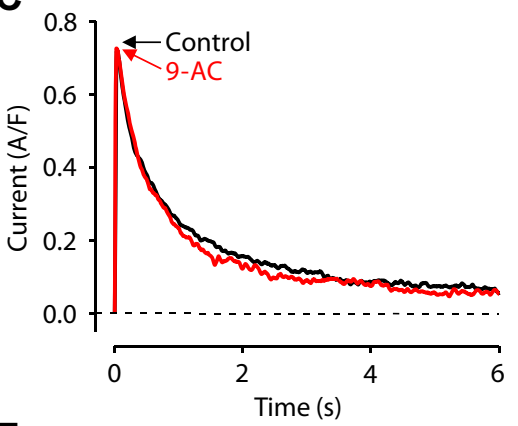

E
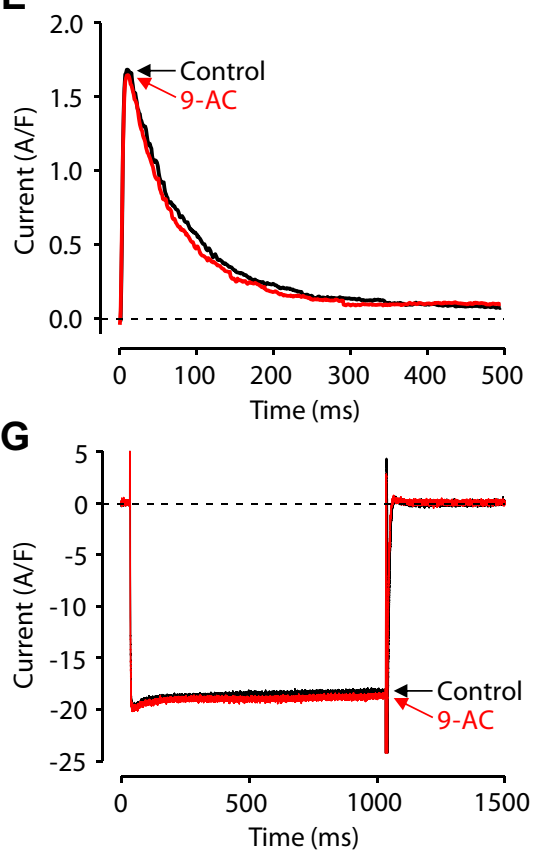

B

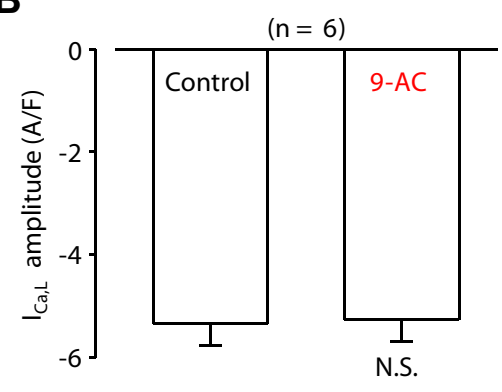

D

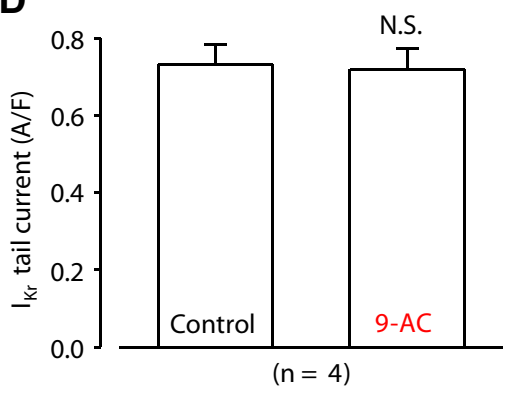

$\mathbf{F}$

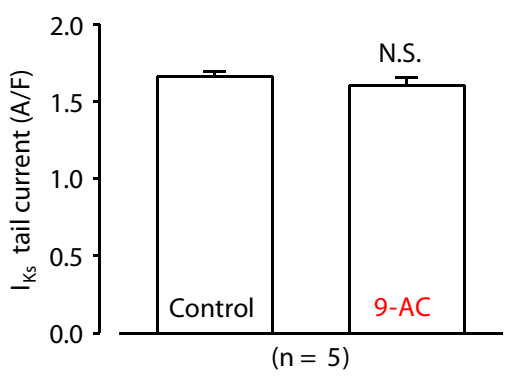

H

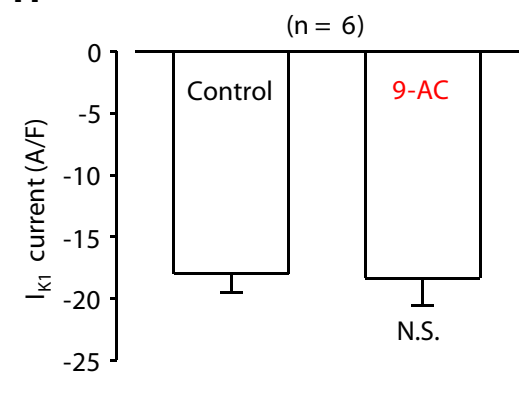


traces (see insert of Fig. 4a), its time course and size greatly resemble those seen on Fig. 1b.

\section{Effects of 9-AC on the rapid component of delayed rectifier potassium current $\left(I_{K r}\right)$}

$\mathrm{I}_{\mathrm{Kr}}$ was activated by 1-s-long depolarizing pulses to $+50 \mathrm{mV}$ arising from the holding potential of $-40 \mathrm{mV}$. This voltage protocol was repeated once in every $20 \mathrm{~s}$. $\mathrm{I}_{\mathrm{Kr}}$ was assessed as tail current amplitudes recorded following repolarization to the holding potential. $\mathrm{I}_{\mathrm{Ca}, \mathrm{L}}$ and the slow component of delayed rectifier potassium current $\left(\mathrm{I}_{\mathrm{Ks}}\right)$ were suppressed by $1 \mu \mathrm{M}$ nisoldipine and $1 \mu \mathrm{M}$ HMR-1556, respectively. The amplitude of the $\mathrm{I}_{\mathrm{Kr}}$ tail currents was unaffected by 9-AC (Fig. $4 \mathrm{c}-\mathrm{d}$ ). In the four studied myocytes, $0.73 \pm 0.05 \mathrm{~A} / \mathrm{F}$ was the density of $\mathrm{I}_{\mathrm{Kr}}$ tail current in control whereas it was $0.72 \pm 0.05 \mathrm{~A} / \mathrm{F}$ in the presence of 9-AC (Fig. 4d).

\section{Effects of 9-AC on the slow component of delayed rectifier potassium current $\left(I_{K S}\right)$}

$\mathrm{I}_{\mathrm{Ks}}$ was also evaluated as a tail current and recorded at the holding potential of $-40 \mathrm{mV}$. The current was activated by 5 s-long depolarizations to $+50 \mathrm{mV}$, and the bathing medium contained $1 \mu \mathrm{M}$ nisoldipine and $1 \mu \mathrm{M}$ E-4031 in order to eliminate $\mathrm{I}_{\mathrm{Ca}, \mathrm{L}}$ and $\mathrm{I}_{\mathrm{Kr}}$, respectively. $\mathrm{I}_{\mathrm{Ks}}$ tail currents were unchanged during $10 \mathrm{~min}$ of 9 -AC perfusion in the five myocytes examined, being $1.66 \pm 0.03$ and $1.61 \pm 0.05 \mathrm{~A} / \mathrm{F}$ in control and in 9-AC, respectively (Fig. 4e-f).

\section{Effects of 9-AC on inward rectifier potassium current $\left(I_{K 1}\right)$}

$\mathrm{I}_{\mathrm{K} 1}$ was recorded with a hyperpolarizing pulse from -80 to $-135 \mathrm{mV}$ applied for $1 \mathrm{~s}$. $\mathrm{I}_{\mathrm{K} 1}$ current was determined at the end of the pulse and showed no change in the six studied cells, being $-18.00 \pm 1.54$ and $-18.36 \pm 2.16 \mathrm{~A} / \mathrm{F}$ in control and in 9-AC, respectively (Fig. 4g-h).

\section{Discussion}

The major finding of this study is that 9-AC is a better tool to study the physiological role of $\mathrm{I}_{\mathrm{Cl}(\mathrm{Ca})}$ in $\mathrm{AP}$ measurements compared with DIDS due to the lack of sodium channel inhibition in case of the former. 9-AC has also no effect on the other main ion currents $\left(\mathrm{I}_{\mathrm{Ca}, \mathrm{L}}, \mathrm{I}_{\mathrm{Kr}}, \mathrm{I}_{\mathrm{Ks}}, \mathrm{I}_{\mathrm{K} 1}\right)$ in ventricular myocytes; however, $\mathrm{I}_{\mathrm{Ca}, \mathrm{L}}$ tracings can be contaminated with $\mathrm{I}_{\mathrm{Cl}(\mathrm{Ca})}$. This can cause problems especially when the decay of $\mathrm{I}_{\mathrm{Ca}, \mathrm{L}}$ is to be fitted by mono- or biexponential functions. The lack of calcium current inhibition by 9-AC in this study is actually in contrast to the result of Walsh and Wang (1996), as, in that study, the same dose of $0.5 \mathrm{mM} 9-\mathrm{AC}$ was reported to cause $60 \%$ inhibition of $\mathrm{I}_{\mathrm{Ca}, \mathrm{L}}$ stimulated by $1-2 \mu \mathrm{M}$ forskolin. A potential explanation of this discrepancy can be the different preparation as they used isolated guinea pig ventricular cells in contrast to the canine myocytes in the present study. Also, forskolin stimulation was not applied in our study. Another report regarding the inhibition of voltage-dependent calcium channels evoked by 9-AC is the review of Kocic (2005), but unfortunately no reference was mentioned there. Other studies, however, found no inhibition of calcium current with $1 \mathrm{mM}$ 9-AC in sheep (Cotton et al. 1997) and rat smooth muscle (Baron et al. 1991) as well as with 0.1 mM 9-AC in rat uterine muscle (Jones et al. 2004) in agreement with the present study.

9-AC just as DIDS reduced the volume-regulated chloride current in guinea pig cardiac myocytes, but none of the two inhibitors altered the isoprenaline-activated chloride currents (Vandenberg et al. 1994). In this study, the volume-regulated chloride current was unlikely to be present as the osmolarity of the perfusion solution was carefully adjusted. Contrary to the results of Vandenberg et al. (1994), 9-AC reduced cAMPdependent chloride channels in guinea pig ventricular myocytes (Levesque et al. 1993; Harvey et al. 1990). It must be noted, however, that protein kinase A-activated chloride current $\left(\mathrm{I}_{\mathrm{Cl}, \mathrm{PKA}}\right)$ is not present either in canine (Sorota et al. 1991) or human heart $(\mathrm{Oz}$ and Sorota 1995).

DIDS is also used very often to study $\mathrm{I}_{\mathrm{Cl}(\mathrm{Ca})}$. The volumeregulated chloride current was blocked by $0.1 \mathrm{mM}$ DIDS by 60 and $100 \%$ in guinea pig (Vandenberg et al. 1994) and in canine atrial myocytes (Sorota 1994), respectively. Unlike 9-AC, DIDS $(1 \mathrm{mM})$ did not reduce $\mathrm{I}_{\mathrm{Cl}, \mathrm{PKA}}$ in guinea pig papillary muscles (Shida et al. 1992); indeed, stimulation was reported in guinea pig ventricular myocytes; however, the author concluded that this was not a direct action on the ion channels but due to an activation of beta-adrenergic receptors (Harvey 1993). DIDS at 10-100 $\mu \mathrm{M}$ enhanced expressed $\mathrm{I}_{\mathrm{sK}}$ channels but had no effects on homopolymeric $\mathrm{K}_{\mathrm{v}} \mathrm{LQT1}$ channel proteins (Busch et al. 1997).

According to the results of the current study, it is likely that DIDS reduces $\mathrm{I}_{\mathrm{Na}}$ as $V_{\max }$ was reduced, and that parameter is an established indicator of fast sodium channel blockade and can be used as an indirect $\mathrm{I}_{\mathrm{Na}}$ measurement (Strichartz and Cohen 1978). Not only DIDS but NFA and NPPB had similar actions on $V_{\max }$ (Zhou et al. 2005). Moreover, both NFA and NPPB reduced $\mathrm{I}_{\mathrm{Na}}$ and induced a leftward shift in its steadystate inactivation as was observed in direct voltage-clamp experiments (Zhou et al. 2005). Indeed, direct evidence exists that DIDS inhibits $\mathrm{I}_{\mathrm{Na}}$ of guinea pig ventricular myocytes with an $\mathrm{EC}_{50}$ of $0.15 \mathrm{mM}$ (Liu et al. 1998). It seems therefore that the inhibition of the $\mathrm{I}_{\mathrm{Na}}$ can be found in case of DIDS but not with 9-AC, in agreement with the results of our previous study (Fülöp et al. 2003) where the reduction of $V_{\max }$ was not found. On the other hand, one must emphasise that DIDS is equally 
useful to study $\mathrm{I}_{\mathrm{Cl}(\mathrm{Ca})}$ during voltage-clamp when $\mathrm{I}_{\mathrm{Na}}$ inhibition is not an issue due to the constant inactivated state of the channels. This is illustrated in an exceptionally convincing way in this study as the actions of the two inhibitors on $\mathrm{I}_{\mathrm{Cl}(\mathrm{Ca})}$ are indistinguishable (Fig. 1). Similar current amplitudes were recorded in the whole examined voltage range by both drugs. This indicates that $\mathrm{I}_{\mathrm{Cl}(\mathrm{Ca})}$ have the same magnitude measured either as $0.2 \mathrm{mM}$ DIDS- or $0.5 \mathrm{mM}$ 9-AC-sensitive current, suggesting that the blocking potency of the two drugs is probably the same. According to the study of Kawano et al. (1995), $0.2 \mathrm{mM}$ DIDS evoked a complete inhibition of $\mathrm{I}_{\mathrm{Cl}(\mathrm{Ca})}$ in rabbit ventricular myocytes, while the reduction of the current by $0.1 \mathrm{mM}$ DIDS was only $70 \%$ in rabbit Purkinje cells (Sipido et al. 1993). It must be noted, however, that, in the latter study, the UV illumination used for intracellular calcium concentration measurements could degrade the inhibitor. Another study performed again on rabbit ventricular myocytes described full inhibition of $\mathrm{I}_{\mathrm{Cl}(\mathrm{Ca})}$ by $0.1 \mathrm{mM}$ DIDS (Zygmunt and Gibbons 1991). Similarly, in murine ventricular cells, $0.1 \mathrm{mM}$ DIDS completely abolished the calcium-activated outward current (Xu et al. 2002) as well as full reduction was found in swine ventricular myocytes by $0.15 \mathrm{mM}$ DIDS ( $\mathrm{Li}$ et al. 2003). In case of 9-AC, much less information is available regarding its $\mathrm{I}_{\mathrm{Cl}(\mathrm{Ca})}$ inhibitory action in direct current measurements. Approximately $90 \%$ reduction was reported by Szigeti et al. (1998) in rabbit heart by $0.5 \mathrm{mM}$ 9-AC. In rat uterine myocytes, $0.1 \mathrm{mM}$ 9-AC greatly reduced $\mathrm{I}_{\mathrm{Cl}(\mathrm{Ca})}$ (Jones et al. 2004). In swine atrial myocytes, $0.2 \mathrm{mM}$ 9-AC as well as $0.2 \mathrm{mM}$ DIDS highly reduced $\mathrm{I}_{\mathrm{Cl}(\mathrm{Ca})}$, causing practically a complete inhibition ( $\mathrm{Li}$ et al. 2004).

DIDS-sensitive current had a characteristic bell-shaped current-voltage relationship (Fig. 1) in agreement with previous studies (Zygmunt and Gibbons 1992; Verkerk et al. 2002). The outward rectification of the channel is clearly demonstrated, and the decrease at high voltages (more positive than $+60 \mathrm{mV}$ ) is presumably caused by the limited $\mathrm{Ca}^{2+}$ entry at these potentials (Fig. 1c). Our measurements were performed not only in the probably more physiological situation, when EGTA or BAPTA was not applied in the pipette solution, but also when $\left[\mathrm{Ca}^{2+}\right]_{\mathrm{i}}$ was strongly buffered (in the presence of $10 \mathrm{mM}$ BAPTA in the pipette solution), clearly demonstrating the calcium-activated nature of the $\mathrm{I}_{\mathrm{Cl}(\mathrm{Ca})}$ (Fig. 1d). The calciumdependence of $\mathrm{I}_{\mathrm{Cl}(\mathrm{Ca})}$ is clearly shown when DIDS-sensitive current amplitude increased in good correlation with the peak value of intracellular calcium concentration upon modification of stimulation rate (Fig. 1h). Intracellular calcium measurements were carried out only in the absence of chloride channel inhibitors as both 9-AC and DIDS were reported to have autofluorescence (Jones et al. 2004; Sipido et al. 1993), respectively. Moreover, the UV illumination used for intracellular calcium concentration measurements could degrade DIDS (Sipido et al. 1993). The increase of calcium transients with high rate of stimulation is similar to what was presented by Sipido et al. (2000). Moreover, the increase of calciumactivated chloride current was also demonstrated, even in the absence of any inhibitor (Sipido et al. 1993). This latter observation suggests that use-dependent blockade of $\mathrm{I}_{\mathrm{Cl}(\mathrm{Ca})}$ by the applied inhibitors is unlikely; however, it cannot be ruled out completely. Unfortunately, according to at least our knowledge, there are no available data regarding the use-dependent nature of $\mathrm{I}_{\mathrm{Cl}(\mathrm{Ca})}$ by any inhibitor.

Interestingly, not only the activation, but the decay of $\mathrm{I}_{\mathrm{Cl}(\mathrm{Ca})}$ was also fairly rapid, as it decreased to near zero within $100 \mathrm{~ms}$ after the onset of the depolarizing pulse just as in two other studies (Zygmunt and Gibbons 1992; Verkerk et al. 2002). This phenomenon is quite opposite compared with that observed with expressed TMEM16A channels, where a maintained component also can be seen (Bradley et al. 2014). This can be a result of the physiological $\left[\mathrm{Ca}^{2+}\right]_{i}$ changes and the remarkable compartmentalization, factors which are much more pronounced in native cardiac myocytes (Trafford et al. 1998; Zhang et al. 2014).

The previously mentioned compartmentalization, together with the known difference in rate of calcium buffering of the two applied buffers (BAPTA is 100 times faster than EGTA, Pásek et al. 2014), can explain the seeming discrepancy of our findings: lack of $\mathrm{I}_{\mathrm{Cl}(\mathrm{Ca})}$ in the presence of BAPTA (Fig. 1d) and the contamination of $\mathrm{I}_{\mathrm{Ca}, \mathrm{L}}$ tracings with $\mathrm{I}_{\mathrm{Cl}(\mathrm{Ca})}$ in the presence of EGTA (Fig. 4a). BAPTA, acting as a fast calcium buffer, is often used to chelate calcium not only in the bulk cytoplasm but also in the subsarcolemmal space, where calcium levels rise to much higher values (Pásek et al. 2014). EGTA, on the contrary, is only capable of reducing calcium levels of the bulk cytoplasm resulting in the cessation of contractions. At the same time, those events, depending on the presence of subsarcolemmal calcium including the calcium-dependent inactivation of L-type calcium current, calcium fluxes via sodium-calcium exchanger and sarcolemmal calcium pump, are hardly affected by EGTA. That is probably the case for $\mathrm{I}_{\mathrm{Cl}(\mathrm{Ca})}$ in this study, explaining the presence of $\mathrm{I}_{\mathrm{Cl}(\mathrm{Ca})}$ even when $10 \mathrm{mM}$ EGTA was applied. Similarly to the present study, BAPTA, but not EGTA (10 mM each), effectively buffered subsarcolemmal calcium in murine ventricular cardiomyocytes (Keskanokwong et al. 2011).

Comparing the actions of the two studied inhibitors on various parameters of the AP, the most important difference was the presence or absence of $V_{\max }$ reduction with DIDS or 9-AC, respectively (Fig. 2e). DIDS was not mentioned to reduce the $V_{\max }$ parameter in rabbit (Verkerk et al. 2004; Hirayama et al. 2002) or in canine (Zygmunt et al. 1997), contrary to the result of the present study. A potential explanation can be the different species or experimental conditions as in the rabbit study whole-cell patch clamp was done instead of the more physiological conventional sharp microelectrode 
recording of the present study. The duration of AP did not always increase by DIDS just as the reduction of phase-1 was not evident in subepicardial myocytes in the study of Verkerk et al. (2004) only after the reduction of $I_{t o 1}$ by 4aminopyridine. The current study however was done on mid-myocardial cells expressing a smaller $\mathrm{I}_{\text {to } 1}$ compared with subepicardial ones (Szabó et al. 2005). In the study of Zygmunt et al. (1997), DIDS did not increase the duration of AP and had no action on either the phase-1 or $V_{\max }$ when whole-cell recording was carried out. It must be noted however that in the pipette solution $20 \mathrm{mM}$ EGTA was used instead of the lack of any calcium buffering in the present study. In case of perforated-patch experiments, again, $0.2 \mathrm{mM}$ DIDS (same dose used in this study) elevated the plateau potential but reduced the value of $\mathrm{APD}_{90}$ and barely had any influence on phase-1 in the study of Zygmunt et al. (1997). A possible explanation for the difference can be again the different type of cell as subepicardial cell was presented in which there are stimulation frequencies where the shortening of the AP was also observed by us (not shown). Another difference is the steady-state pacing used in this study and the lack of that in the study of Zygmunt et al. (1997). The effect of DIDS on the duration of the AP was similar in rabbit ventricular myocytes (Hirayama et al. 2002) to what was the case in the present study, namely prolongation of the AP. On the contrary, no marked action on phase-1 was shown in that work which could be due to again the whole-cell patch-clamp recording in that work versus the conventional sharp microelectrode recording in the present study.

As was demonstrated, the action of the two studied inhibitors on various AP parameters were largely identical (except those on $V_{\max }$ and AP amplitude), although slight differences in phase-1 and plateau potential changes induced by the two drugs were seen (Fig. 2d, f). A greater reduction of phase- 1 was seen at long cycle lengths ( 2 and 5 s, Fig. 2d) with 9-AC. The magnitude of phase-1 depends on many ion currents including $\mathrm{I}_{\mathrm{Na}}, \mathrm{I}_{\mathrm{to}}, \mathrm{I}_{\mathrm{Cl}(\mathrm{Ca})}$ and $\mathrm{I}_{\mathrm{Ca}, \mathrm{L}}$ and the precise timing of their activation, inactivation and reactivation. DIDS was shown earlier to reduce at least three of these $\left(\mathrm{I}_{\mathrm{Na}}, \mathrm{I}_{\mathrm{Cl}(\mathrm{Ca})}\right.$ and $\left.\mathrm{I}_{\mathrm{Ca}, \mathrm{L}}\right)$ whereas there is no evidence that 9-AC reduces any other current apart from $\mathrm{I}_{\mathrm{Cl}(\mathrm{Ca})}$. Moreover, the rate-dependence of these currents can complicate the picture as phase-1 magnitude itself shows reverse rate-dependence having larger values at longer cycle lengths mainly due to two factors working simultaneously. First, the slow recovery from inactivation of $\mathrm{I}_{\mathrm{tol}}$, which decreases the amplitude of $\mathrm{I}_{\text {to1 }}$ at increasing heart rates (Wang et al. 1999), and secondly, $\mathrm{I}_{\mathrm{Ca}, \mathrm{L}}$ increases with the reduction of cycle length in a $\mathrm{Ca}^{2+}$-calmodulin protein kinase (CaMKII)-dependent regulatory pathway (also called as $\mathrm{Ca}^{2+}$ current facilitation), resulting in an earlier elevation of the AP plateau (Bers and Morotti 2014). Thus, the direct rate-dependent effect of 9-AC on phase-1 magnitude could be the result of clear-cut inhibition of $\mathrm{I}_{\mathrm{Cl}(\mathrm{Ca})}$, in which current is increasing at higher stimulatory frequencies as it probably follows the frequency-dependent properties of the $\mathrm{Ca}^{2+}$ entry and calcium transients (see earlier in "Discussion") while the reverse rate-dependent effect of DIDS on phase- 1 could be attributed to an almost constant $\mathrm{I}_{\mathrm{Na}}$ blockade, reflecting the general feature of frequencydependence of phase-1 magnitude. Therefore, the difference in rate-dependent inhibition of phase-1 by the two studied blockers can simply be due to weaker selectivity of DIDS.

The reverse rate-dependency of AP lengthening after the application of either DIDS or 9-AC shows the intrinsic property of APD modulation rather than the frequencydependence of the blocked ion current (Bányász et al. 2009).

The effect of DIDS on plateau potential was small but statistically significant and did not depend on stimulation rate. On the contrary, 9-AC increased plateau potential in a direct rate-dependent manner resulting in the smaller effect of DIDS at short cycle lengths $(0.3$ and $0.5 \mathrm{~s}$, Fig. $2 \mathrm{f})$. The weaker selectivity of DIDS can provide again a possible explanation as the reduction of $\mathrm{I}_{\mathrm{Ca}, \mathrm{L}}$ likely causes the reduction of plateau potential (or more precisely the smaller increase of that) compared with 9-AC which was actually the case at all studied cycle lengths.

Concentration-dependent effect of 9-AC on ventricular AP was also studied. Concentrations of 9-AC were ranging from 0.1 to $1 \mathrm{mM}$ to achieve chloride channel inhibition in the literature (Szigeti et al. 1998; Walsh and Wang 1996). The reduction in phase-1 magnitude just as the lengthening of AP was saturated at $0.5 \mathrm{mM}$ of 9-AC as $1 \mathrm{mM} 9-\mathrm{AC}$ did not increase these changes much further (both $\mathrm{APD}_{90}$ and phase-1 magnitude values did not differ significantly in the presence of 0.5 and $1 \mathrm{mM} 9-\mathrm{AC}$, Fig. 3b-c). The half-effective doses, determined from 9-AC-induced changes of two AP parameters, were very similar to each other $(167.2 \pm 12.4$ and $158.2 \pm$ $8.2 \mu \mathrm{M}$ in cases of phase- 1 magnitude and $\mathrm{APD}_{90}$, respectively). Moreover, even the values of Hill coefficients were close being $2.04 \pm 0.22$ and $1.81 \pm 0.13$ in cases of phase- 1 magnitude and $\mathrm{APD}_{90}$, respectively. It must be noted, however, that both parameters (phase-1 magnitude and $\mathrm{APD}_{90}$ ) depend on not only one ionic current, but also on the fine-tuned interplay between several ionic currents, including $\mathrm{I}_{\mathrm{to}}, \mathrm{I}_{\mathrm{Na}}$ and $\mathrm{I}_{\mathrm{Ca}, \mathrm{L}}$ in case of phase-1 magnitude and even more in $\mathrm{APD}_{90}$. Therefore, this must be kept in mind when comparing these half-effective doses with data available in the literature. The half-inhibitory dose of 9AC on TMEM16A currents in HEK 293 cells that stably expressed human TMEM16A was reported to be $58 \mu \mathrm{M}$ (Bradley et al. 2014). Calcium-sensitive chloride current was reduced by 9-AC with a half-inhibitory dose of $80 \mu \mathrm{M}$ on brown fat cells (Pappone and Lee 1995). The $\mathrm{EC}_{50}$ of 9-AC was higher in our study comparing to the other two recently mentioned reports. It is hard to compare these results and find a possible explanation for the 
less potent effect of 9-AC in our case for multiple reasons. One reason might be, for instance, the totally different preparation, as canine ventricular myocytes were used in our study whereas brown fat cells and TMEM16Aexpressing cells were used in the other two. Secondly, direct ion current measurements were made in the other studies whereas we calculated half-effective concentrations based on the actions of 9-AC on the cardiac AP (see above). It is worth emphasizing that our $\mathrm{EC}_{50}$ values were almost identical regardless of which AP parameter was used to determine those. This suggests that both the lengthening of AP and the reduction of phase-1 magnitude is likely to be the result of 9-AC-induced $\mathrm{I}_{\mathrm{Cl}(\mathrm{Ca})}$ inhibition. Comparing the Hill coefficients with values available in literature is not possible as, according at least to our knowledge, this is the first report available for such value in case of 9-AC. Moreover, Hill coefficients are not mentioned in case of other inhibitors such as DIDS or any other often used ones. From our results, one can draw the conclusion that the application of $9-\mathrm{AC}$ in $0.5 \mathrm{mM}$ dose is suitable to examine $\mathrm{I}_{\mathrm{Cl}(\mathrm{Ca})}$ as that dose completely inhibits the chloride current (see earlier in "Discussion") and its actions on the morphology of the AP are saturated.

In conclusion, there was no difference in the actions of DIDS and 9-AC on $\mathrm{I}_{\mathrm{Cl}(\mathrm{Ca})}$ examined with standard, rectangular voltage pulses. DIDS, however, significantly blocks fast sodium channels; therefore, it is not suitable in AP measurements, when the investigation focuses on the physiological role of $\mathrm{I}_{\mathrm{Cl}(\mathrm{Ca})}$ in the formation of APs. The difference between the action of the blockers on AP is becoming even more pronounced at increasing heart rates, resulting in the fact that DIDS but not 9-AC fails to demonstrate the frequencydependent properties of $\mathrm{I}_{\mathrm{Cl}(\mathrm{Ca})}$. Other major ventricular ion currents $\left(\mathrm{I}_{\mathrm{Ca}, \mathrm{L}}, \mathrm{I}_{\mathrm{Kr}}, \mathrm{I}_{\mathrm{Ks}}, \mathrm{I}_{\mathrm{K} 1}\right)$ were not affected by $9-\mathrm{AC}$ in a dose $(0.5 \mathrm{mM})$ close to that completely blocks chloride channels. However, in native cells, L-type calcium current tracings can be contaminated with $\mathrm{I}_{\mathrm{Cl}(\mathrm{Ca})}$ using physiological ion composition, resulting in difficulty when inactivation kinetics of $\mathrm{I}_{\mathrm{Ca}, \mathrm{L}}$ is about to be determined in the absence of the $\mathrm{I}_{\mathrm{Cl}(\mathrm{Ca})}$ blockade.

\begin{abstract}
Acknowledgments Financial support was provided by grants from the Hungarian Scientific Research Fund (OTKA-PD101171, OTKAK100151, OTKA-K101196, OTKA-K109736 and OTKA-NK104331). Further support was obtained from the Hungarian Government (TÁMOP4.2.2.A-11/1/KONV-2012-0045). This research was realised in the frames of TÁMOP 4.2.4. A/2-11-1-2012-0001 "National Excellence Program-Elaborating and operating an inland student and researcher personal support system convergence program". The project was subsidised by the European Union and co-financed by the European Social Fund. This paper was supported by the János Bolyai Research Scholarship of the Hungarian Academy of Sciences.
\end{abstract}

Conflict of interest The authors declare that they have no conflict of interest.

\section{References}

Bányász T, Horváth B, Virág L, Bárándi L, Szentandrássy N, Harmati G, Magyar J, Marangoni S, Zaza A, Varró A, Nánási PP (2009) Reverse rate dependency is an intrinsic property of canine cardiac preparations. Cardiovasc Res 84:237-244. doi:10.1093/cvr/cvp213, PMID: 19556280

Baron A, Pacaud P, Loirand G, Mironneau C, Mironneau J (1991) Pharmacological block of $\mathrm{Ca}(2+)$-activated $\mathrm{Cl}$ - current in rat vascular smooth muscle cells in short-term primary culture. Pflugers Arch 419:553-558. doi:10.1007/BF00370294, PMID: 1664933

Bers DM, Morotti S (2014) $\mathrm{Ca}(2+)$ current facilitation is CaMKIIdependent and has arrhythmogenic consequences. Front Pharmacol 5:144. doi:10.3389/fphar.2014.00144, PMID: 24987371

Bradley E, Fedigan S, Webb T, Hollywood MA, Thornbury KD, McHale NG, Sergeant GP (2014) Pharmacological characterization of TMEM16A currents. Channels (Austin) 8:308-320. doi:10.4161/ chan.28065, PMID: 24642630

Busch AE, Busch GL, Ford E et al (1997) The role of the IsK protein in the specific pharmacological properties of the IKs channel complex. Br J Pharmacol 122:187-189. doi:10.1038/sj.bjp.0701434, PMID: 9313924

Cotton KD, Hollywood MA, McHale NG, Thornbury KD (1997) Ca2+ current and $\mathrm{Ca}(2+)$-activated chloride current in isolated smooth muscle cells of the sheep urethra. J Physiol 505:121-131. doi:10. 1111/j.1469-7793.1997.121bc.x, PMID: 9409476

Dam VS, Boedtkjer DM, Nyvad J, Aalkjaer C, Matchkov V (2014) TMEM16A knockdown abrogates two different $\mathrm{Ca}(2+)$-activated $\mathrm{Cl}(-)$ currents and contractility of smooth muscle in rat mesenteric small arteries. Pflugers Arch 466:1391-1409. doi:10.1007/s00424013-1382-1, PMID: 24162234

Duan D (2009) Phenomics of cardiac chloride channels: the systematic study of chloride channel function in the heart. J Physiol 587:21632177. doi:10.1113/jphysiol.2008.165860, PMID: 19171656

Eggermont J (2004) Calcium-activated chloride channels: (un)known, (un)loved? Proc Am Thorac Soc 1:22-27. doi:10.1513/pats. 2306010, PMID: 16113407

Fishman GI, Chugh SS, Dimarco JP et al (2010) Sudden cardiac death prediction and prevention: report from a National Heart, Lung, and Blood Institute and Heart Rhythm Society Workshop. Circulation 122:2335-2348. doi:10.1161/CIRCULATIONAHA.110.976092, PMID: 21147730

Forrest AS, Joyce TC, Huebner ML et al (2012) Increased TMEM16Aencoded calcium-activated chloride channel activity is associated with pulmonary hypertension. Am J Physiol Cell Physiol 303: C1229-C1243. doi:10.1152/ajpcell.00044.2012, PMID: 23034390

Fülöp L, Fiák E, Szentandrássy N, Magyar J, Nánási PP, Bányász T (2003) The role of transmembrane chloride current in afterdepolarisations in canine ventricular cardiomyocytes. Gen Physiol Biophys 22:341-353, PMID: 14986885

Fülöp L, Bányász T, Magyar J, Szentandrássy N, Varró A, Nánási PP (2004) Reopening of L-type calcium channels in human ventricular myocytes during applied epicardial action potentials. Acta Physiol Scand 180:39-47. doi:10.1046/j.0001-6772.2003.01223.x, PMID: 14706111

Guo D, Young L, Patel C, Jiao Z, Wu Y, Liu T, Kowey PR, Yan GX (2008) Calcium-activated chloride current contributes to action potential alternations in left ventricular hypertrophy rabbit. Am J Physiol Heart Circ Physiol 295:H97-H104. doi:10.1152/ajpheart. 01032.2007, PMID: 18441200

Hamill OP, Marty A, Neher E, Sakmann B, Sigworth FJ (1981) Improved patch-clamp techniques for high-resolution current recording from cells and cell-free membrane patches. Pflugers Arch 391:85-100. doi:10.1007/BF00656997, PMID: 6270629 
Harvey RD (1993) Effects of stilbenedisulfonic acid derivatives on the cAMP-regulated chloride current in cardiac myocytes. Pflugers Arch 422:436-442. doi:10.1007/BF00375068, PMID: 8386352

Harvey RD, Clark CD, Hume JR (1990) Chloride current in mammalian cardiac myocytes. Novel mechanism for autonomic regulation of action potential duration and resting membrane potential. J Gen Physiol 95:1077-1102. doi:10.1085/jgp.95.6.1077, PMID: 2165130

Hirayama Y, Kuruma A, Hiraoka M, Kawano S (2002) Calcium-activated $\mathrm{Cl}$ - current is enhanced by acidosis and contributes to the shortening of action potential duration in rabbit ventricular myocytes. Jpn J Physiol 52:293-300. doi:10.2170/jjphysiol.52.293, PMID: 12230806

Jones K, Shmygol A, Kupittayanant S, Wray S (2004) Electrophysiological characterization and functional importance of calcium-activated chloride channel in rat uterine myocytes. Pflugers Arch 448: 36-43. doi:10.1007/s00424-003-1224-7, PMID: 14740218

Kawano S, Hirayama Y, Hiraoka M (1995) Activation mechanism of $\mathrm{Ca}(2+)$-sensitive transient outward current in rabbit ventricular myocytes. J Physiol 486:593-604, PMID: 7473222

Keskanokwong T, Lim HJ, Zhang P, Cheng J, Xu L, Lai D, Wang Y (2011) Dynamic Kv4.3-CaMKII unit in heart: an intrinsic negative regulator for CaMKII activation. Eur Heart J 32:305-315. doi:10. 1093/eurheartj/ehq469, PMID: 21148163

Kocic I (2005) Modulators of ion channels activated by hypotonic swelling in cardiomyocytes: new perspectives for pharmacological treatment of life-threatening arrhythmias. Curr Med Chem Cardiovasc Hematol Agents 3:333-339. doi:10.2174/156801605774322274, PMID: 16250864

Levesque PC, Clark CD, Zakarov SI, Rosenshtraukh LV, Hume JR (1993) Anion and cation modulation of the guinea-pig ventricular action potential during beta-adrenoceptor stimulation. Pflugers Arch 424:54-62. doi:10.1007/BF00375102, PMID: 8394573

Li GR, Du XL, Siow YL, O K, Tse HF, Lau CP (2003) Calcium-activated transient outward chloride current and phase 1 repolarization of swine ventricular action potential. Cardiovasc Res 58:89-98. doi: 10.1016/S0008-6363(02)00859-3, PMID: 12667949

Li GR, Sun H, To J, Tse HF, Lau CP (2004) Demonstration of calciumactivated transient outward chloride current and delayed rectifier potassium currents in Swine atrial myocytes. J Mol Cell Cardiol 36:495-504. doi:10.1016/j.yjmcc.2004.01.005, PMID: 15081309

Liu J, Lai ZF, Wang XD, Tokutomi N, Nishi K (1998) Inhibition of sodium current by chloride channel blocker $4,4^{\prime}$ diisothiocyanatostilbene-2,2'-disulfonic acid (DIDS) in guinea pig cardiac ventricular cells. J Cardiovasc Pharmacol 31:558-567. doi: 10.1097/00005344-199804000-00014, PMID: 9554805

Oz MC, Sorota S (1995) Forskolin stimulates swelling-induced chloride current, not cardiac cystic fibrosis transmembrane-conductance regulator current, in human cardiac myocytes. Circ Res 76:1063-1070. doi:10.1161/01.RES.76.6.1063, PMID: 7538915

Pappone PA, Lee SC (1995) Alpha-adrenergic stimulation activates a calcium-sensitive chloride current in brown fat cells. J Gen Physiol 106:231-258. doi:10.1085/jgp.106.2.231, PMID: 8537817

Parameswaran S, Kumar S, Verma RS, Sharma RK (2013) Cardiomyocyte culture - an update on the in vitro cardiovascular model and future challenges. Can J Physiol Pharmacol 91:985-998. doi:10.1139/cjpp-2013-0161, PMID: 24289068

Pásek M, Simurda J, Orchard CH (2014) Effect of Ca2+ efflux pathway distribution and exogenous $\mathrm{Ca} 2+$ buffers on intracellular $\mathrm{Ca} 2+$ dynamics in the rat ventricular myocyte: a simulation study. Biomed Res Int 2014:920208. doi:10.1155/2014/920208, PMID: 24971358

Pedemonte N, Galietta LJ (2014) Structure and function of TMEM16 proteins (anoctamins). Physiol Rev 94:419-459. doi:10.1152/ physrev.00039.2011, PMID: 24692353
Schmitt N, Grunnet M, Olesen SP (2014) Cardiac potassium channel subtypes: new roles in repolarization and arrhythmia. Physiol Rev 94:609-653. doi:10.1152/physrev.00022.2013, PMID: 24692356

Shida S, Nakaya H, Kanno M (1992) Effects of Cl- channel blockers on beta-adrenoceptor-mediated decreases in resting potential and intracellular Cl- activity in guinea-pig heart. Eur J Pharmacol 212:267270. doi:10.1016/0014-2999(92)90341-Z, PMID: 1318214

Sipido KR, Callewaert G, Carmeliet E (1993) [Ca2+]i transients and $[\mathrm{Ca} 2+] \mathrm{i}-d e p e n d e n t$ chloride current in single Purkinje cells from rabbit heart. J Physiol 468:641-667, PMID: 8254529

Sipido KR, Volders PG, de Groot SH et al (2000) Enhanced $\mathrm{Ca}(2+)$ release and $\mathrm{Na} / \mathrm{Ca}$ exchange activity in hypertrophied canine ventricular myocytes: potential link between contractile adaptation and arrhythmogenesis. Circulation 102:2137-2144. doi:10.1161/01. CIR.102.17.2137, PMID: 11044433

Song J, Zhang X, Qi Z et al (2009) Cloning and characterization of a calcium-activated chloride channel in rat uterus. Biol Reprod 80: 788-794. doi:10.1095/biolreprod.108.071258, PMID: 19144963

Sorota S (1994) Pharmacologic properties of the swelling-induced chloride current of dog atrial myocytes. J Cardiovasc Electrophysiol 5:10061016. doi:10.1111/j.1540-8167.1994.tb01143.x, PMID: 7697203

Sorota S, Siegal MS, Hoffman BF (1991) The isoproterenol-induced chloride current and cardiac resting potential. J Mol Cell Cardiol 23: 1191-1198. doi:10.1016/0022-2828(91)90207-3, PMID: 1749007

Strichartz G, Cohen I (1978) Vmax as a measure of GNa in nerve and cardiac membranes. Biophys J 23:153-156. doi:10.1016/S00063495(78)85440-X, PMID: 667304

Szabó G, Szentandrássy N, Bíró T, Tóth BI, Czifra G, Magyar J, Bányász T, Varró A, Kovács L, Nánási PP (2005) Asymmetrical distribution of ion channels in canine and human left-ventricular wall: epicardium versus midmyocardium. Pflugers Arch 450:307-316. doi:10. 1007/s00424-005-1445-z, PMID: 15952036

Szentandrássy N, Nagy D, Ruzsnavszky F et al (2011) Powerful technique to test selectivity of agents acting on cardiac ion channels: the action potential voltage-clamp. Curr Med Chem 18:3737-3756. doi: 10.2174/092986711796642418, PMID: 21774754

Szigeti G, Rusznák Z, Kovács L, Papp Z (1998) Calcium-activated transient membrane currents are carried mainly by chloride ions in isolated atrial, ventricular and Purkinje cells of rabbit heart. Exp Physiol 83:137-153, PMID: 9568474

Trafford AW, Díaz ME, Eisner DA (1998) Ca-activated chloride current and $\mathrm{Na}-\mathrm{Ca}$ exchange have different timecourses during sarcoplasmic reticulum $\mathrm{Ca}$ release in ferret ventricular myocytes. Pflugers Arch 435:743-745. doi:10.1007/s004240050577, PMID: 9479029

Vandenberg JI, Yoshida A, Kirk K, Powell T (1994) Swelling-activated and isoprenaline-activated chloride currents in guinea pig cardiac myocytes have distinct electrophysiology and pharmacology. J Gen Physiol 104:997-1017. doi:10.1085/jgp.104.6.997, PMID: 7699368

Verkerk AO, Wilders R, Zegers JG, van Borren MM, Ravesloot JH, Verheijck EE (2002) $\mathrm{Ca}(2+)$-activated $\mathrm{Cl}(-)$ current in rabbit sinoatrial node cells. J Physiol 540:105-117. doi:10.1113/jphysiol.2001. 013184, PMID: 11927673

Verkerk AO, Tan HL, Ravesloot JH (2004) Ca2+-activated Cl- current reduces transmural electrical heterogeneity within the rabbit left ventricle. Acta Physiol Scand 180:239-247. doi:10.1111/j.00016772.2003.01252.x, PMID: 14962005

Walsh KB, Wang C (1996) Effect of chloride channel blockers on the cardiac CFTR chloride and L-type calcium currents. Cardiovasc Res 32:391-399. doi:10.1016/0008-6363(96) 00075-2, PMID: 8796127

Wang HS, Dixon JE, McKinnon D (1997) Unexpected and differential effects of Cl- channel blockers on the Kv4.3 and Kv4.2 K+ channels. Implications for the study of the I(to2) current. Circ Res 81: 711-718. doi:10.1161/01.RES.81.5.711, PMID: 9351445

Wang Z, Feng J, Shi H, Pond A, Nerbonne JM, Nattel S (1999) Potential molecular basis of different physiological properties of the transient 
outward $\mathrm{K}+$ current in rabbit and human atrial myocytes. Circ Res 84:551-561. doi:10.1161/01.RES.84.5.551, PMID: 10082477

Xu Y, Dong PH, Zhang Z, Ahmmed GU, Chiamvimonvat N (2002) Presence of a calcium-activated chloride current in mouse ventricular myocytes. Am J Physiol Heart Circ Physiol 283:H302-H314. doi:10.1152/ajpheart.00044.2002, PMID: 12063303

Yang YD, Cho H, Koo JY et al (2008) TMEM16A confers receptoractivated calcium-dependent chloride conductance. Nature 455: 1210-1215. doi:10.1038/nature07313, PMID: 18724360

Zhang S, Chen Y, An H, Liu H, Li J, Pang C, Ji Q, Zhan Y (2014) A novel biophysical model on calcium and voltage dual dependent gating of calcium-activated chloride channel. J Theor Biol 355:229-235. doi: 10.1016/j.jtbi.2014.04.004, PMID: 24727189

Zheng XB, Wang R, Yang HL, Sun XL (2013) Effects of chloride ion channel and its blockers on myocardial ischemia reperfusion arrhythmias in rabbits. Zhonghua Yi Xue Za Zhi 93:1168-1173, PMID: 23902890

Zhou SS, Gao Z, Dong L, Ding YF, Zhang XD, Wang YM, Pei JM, Gao F, Ma XL (2002) Anion channels influence ECC by modulating L-type $\mathrm{Ca}(2+)$ channel in ventricular myocytes. J Appl Physiol 93:1660-1668. doi:10. 1152/japplphysiol.00220.2002, PMID: 12381751
Zhou SS, Yang J, Li YQ, Zhao LY, Xu M, Ding YF (2005) Effect of Clchannel blockers on aconitine-induced arrhythmias in rat heart. Exp Physiol 90:865-872. doi:10.1113/expphysiol.2005.031484, PMID: 16118235

Zhou SS, Zhang LB, Sun WP, Xiao FC, Zhou YM, Li YJ, Li DL (2007) Effects of monocarboxylic acid-derived Cl- channel blockers on depolarization-activated potassium currents in rat ventricular myocytes. Exp Physiol 92:549-559. doi:10.1113/expphysiol.2007. 037069, PMID: 17303647

Zygmunt AC (1994) Intracellular calcium activates a chloride current in canine ventricular myocytes. Am J Physiol 267:H1984-H1995, PMID: 7977830

Zygmunt AC, Gibbons WR (1991) Calcium-activated chloride current in rabbit ventricular myocytes. Circ Res 68:424-437. doi:10.1161/01. RES.68.2.424, PMID: 1991347

Zygmunt AC, Gibbons WR (1992) Properties of the calcium-activated chloride current in heart. J Gen Physiol 99:391-414. doi:10.1085/ jgp.99.3.391, PMID: 1375275

Zygmunt AC, Robitelle DC, Eddlestone GT (1997) Ito1 dictates behavior of $\mathrm{ICl}(\mathrm{Ca})$ during early repolarization of canine ventricle. Am J Physiol 273:H1096-H1106, PMID: 9321794 